\title{
Performance comparison of field oriented control based permanent magnet synchronous motor fed by matrix converter using PI and IP speed controllers
}

\author{
Mohamed Bouazdia ${ }^{1}$, Mohamed Bouhamida $^{2}$, Rachid Taleb $^{3}$, Mouloud Denai $^{4}$ \\ ${ }^{1,2}$ Automatic Control Department, Mohamed Boudiaf University of Science and Technology, Algeria \\ Laboratoire Automatisation, Vision et Contrôle Intelligent des Systèmes (AVCIS) \\ ${ }^{3}$ Electrical Engineering Department, Hassiba Benbouali University, LGEER Laboratory, Algeria \\ ${ }^{4}$ School of Engineering and Technology, University of Hertfordshire, United Kingdom
}

\section{Article Info \\ Article history: \\ Received Jan 2, 2020 \\ Revised Mar 22, 2020 \\ Accepted Apr 2, 2020}

\section{Keywords:}

Field oriented control

Matrix converter

Permanent magnet synchronous machine

PI and IP controller

\begin{abstract}
This paper focuses on modeling and closed-loop speed control of a threephase permanent magnet synchronous motor (PMSM) fed by a matrix converter (MC) based on field-oriented control (FOC). The model considers a set of a small input filter with supply impedance or cable effect, to improve the quality of the input current. A simplified form of the Venturini modulation algorithm is used for switching the matrix converter and a comparative study of two types of speed controllers is presented, namely a proportional integral (PI) and a proportional integral (PI) to improve performances of the drive system in transient and stable conditions. The overall drive system is simulated using Matlab/Simulink environment. The motor performance is evaluated under different operating conditions such as sudden changes in the load or changes in the angular speed reference. The results of the converter MC gives unlimited output frequency, sinusoidal input current and output voltage waveforms and unity input displacement factor. The IP controller is shown to achieve better performance of the speed control loop, with or without the load torque as compared to the PI classic controller.
\end{abstract}

Copyright $(2020$ Institute of Advanced Engineering and Science. All rights reserved.

\section{Corresponding Author:}

Mohamed BOUAZDIA,

Automatic Control Department,

Mohamed Boudiaf University of Science and Technology,

Oran, Algeria.

Email: mo.bouazdia@gmail.com

\section{INTRODUCTION}

Permanent-magnet synchronous motors (PMSMs) are widely used in low and mid power applications such as in variable-speed drives, wind generation systems, electric vehicles and robotics, etc. PMSMs do not carry rotor currents. Moreover, eliminating copper in the rotor allows the design of machines with smaller rotor diameters, resulting in smaller machine size with higher power density and lower rotor inertia [1-2]. Thesefeatures contribute to the improvement of the efficiency of PMSMs as compared to induction motors (IM). Field oriented control (FOC) or vector control theory has become now a widely accepted solution for the control of AC motors drives [3-5]. Matrix converter-fed PMSM drives combine the advantages and attractive features of both the motor and converters technologies, and are emerging as a competing candidate drive technology for applications that require power-dense and volumetrically efficient electromechanical energy conversion with minimal distortion of supply-side power quality. One of the most attractive feature of matrix converters (MC) when compared to conventional voltage source inverter and active-rectifier combinations is the absence of a large DC link capacitance, since for high power applications this is a relatively expensive and bulky component which is widely recognized as having a significantly 
higher failure rate than other components. Hence, MCs are potentially attractive for aerospace applications, for example, for which reliability and weight are crucial [6-8], For example, by using Venturini's modulation technique in its simplified form, MCs are capable of providing simultaneous amplitude and frequency transformation of a three-phase voltage system and allow a wide range of output voltage, with desirable features, such as sinusoidal input and output waveforms, bi-directional energy flow capability, and with adjustable displacement angle (i.e. controllable input power factor) on the mains side under certain conditions [9-10], and high power/volume ratio. However, the switching of this type of converter generates harmonics which are commonly-called cutting. The effect of these harmonics has not been studied in detail in the current literature because the network to which the converter is connected was assumed to be perfect. This is obviously not the case since a direct connection can lead to major problems. To eliminate these harmonics cutting, a filter is inserted between the converter and the network in most compensating tension. A low pass filter can achieve that target. So in a MC-fed drive system, the input filter is usually included to meet the input power quality standard (to smooth the pulsed currents) to reduce input voltage distortion and to ensure the overall system stability [6, 11]. A FOC-controlled PMSM drive provides better dynamic response and less torque ripples, and requires only a constant switching frequency. The outer speed control loop in vector control greatly affects the system performance. Proportional integral (PI) regulators are usually preferred, but because they provide forward compensation, their performance is affected by load disturbances and variable speeds [12-14]. To overcome these problems, an integral proportional (IP) speed controller is proposed in this work [15-17]. IP control, in contrast to PI, providesa feedback compensation. The IP controller is designed to achieve zero steady-state error, minimum overshoot and minimum settling time. At the same time, this controller can guarantee both enhanced robustness and closed-loop stability of the PMSM drive system over the existing control strategies. A comparative simulation study of the performance of the PI and IP regulators is presented.

The remaining of the paper is organized as follows: Section 2 presents the model of the overall system and its implementation in Matlab/Simulink. In Section 3, the proposed control scheme is described and all the different controllers are derived. Section 4 presents and discusses the simulation results for various operating conditions such as variable speed and load. Section 5 summarises the conclusions of the paper.

\section{MODELING OF THE MATRIX CONVERTER FED PM MOTOR DRIVE SYSTEM}

Figure 1 shows the schematic of a matrix converter fed PM synchronous motor (PMSM) drive system. A second-order RLC filter with resistance $R_{f}$, inductance $L_{f}$ and capacitance $C_{f}$ is used. The combined effect of a non-ideal AC source and three phase cables is represented by the resistance $R_{S}$ and inductance $L_{s}$. The dynamic models of the PMSM drive, MC, and input filter are presented next.

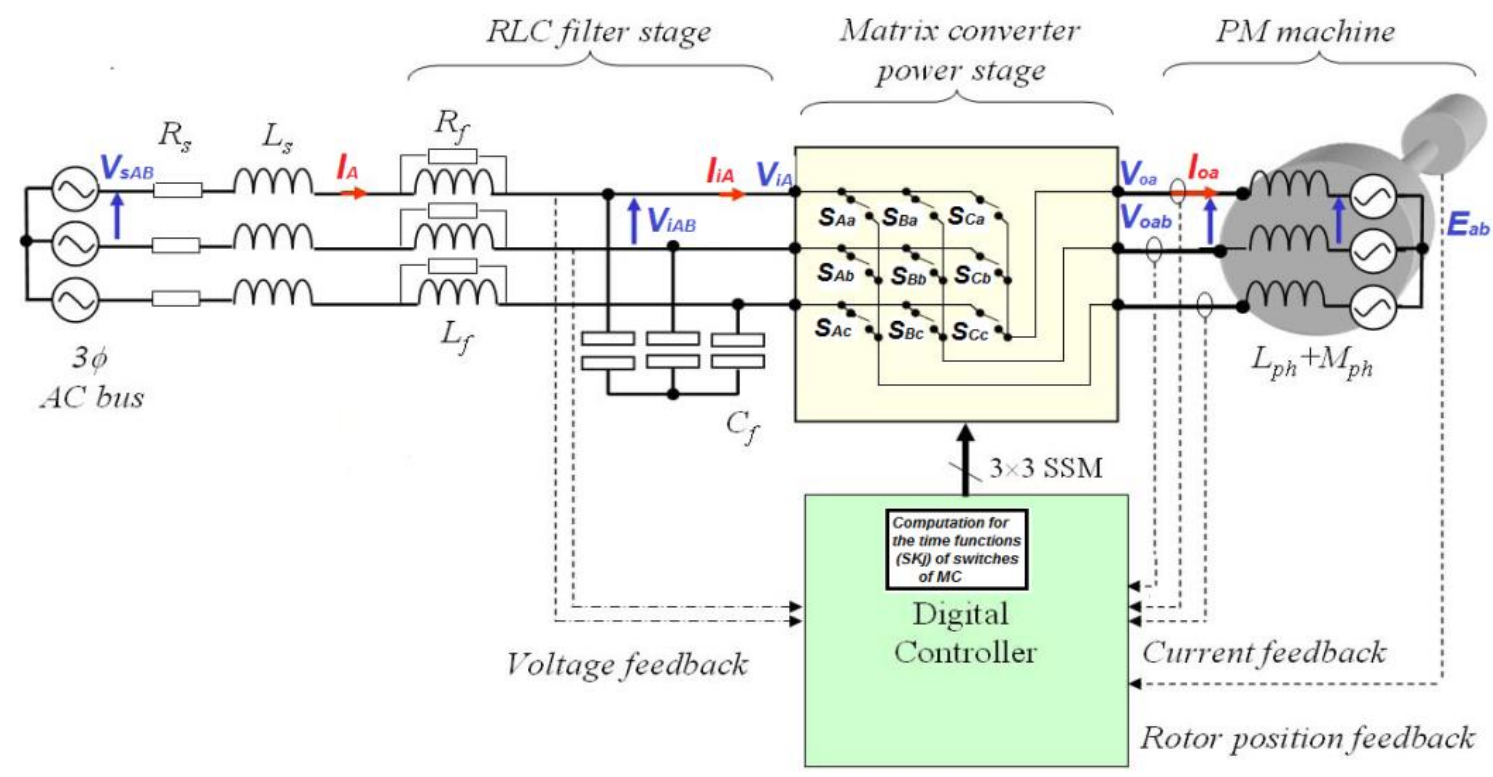

Figure 1. Circuit diagram of the MC-fed PM brushless AC motor drive system 


\subsection{The input filter}

A low-pass filter is used at the input side of the MC to reduce the harmonics due to the switching frequency. The dynamic equations for the input filter can be derived from the circuit laws and they are detailed in [18-19] where it has been assumed that the damping resistor in parallel with $L_{f}$ is not present, or $R_{f}$ isinfinite. Using a similar notation, the combined inductance is $L=L_{s}+L_{f}$, where $L_{s}$ represents the effect of the cable inductance and $L_{f}$ is the filter inductor. Let $r$ be the sum of the cable resistance $R_{S}$ and the parasitic resistance of the filter inductor. The filter requirements are as follows:

a) The cutoff frequency must be lower than the switching frequency:

$$
\omega_{0}=\frac{1}{\sqrt{C_{f} L_{f}}}
$$

where $L_{f}$ and $C_{f}$ are the inductance and capacitance and $\omega_{0}=2 \pi f_{o}$ is the resonance pulsation of the input filter.

b) Minimize its reactive power at the power grid frequency.

c) Minimize the volume and weight of the capacitor and chokes.

d) Minimize the inductance voltage drop at the rated current to avoid a reduction in the voltage transfer ratio.

Firstly, the cutoff frequency of the $L C$ filter is chosen to provide the desired attenuation at the switching frequency. The value of the capacitor or the inductor is calculated based on one of the above criteria.

\subsection{Matrix converter}

Matrix converters which directly connect the AC supply to an AC load are made up of bidirectional switches arranged in a matrix form. In a three phase in three-phase out matrix converter there are nine bidirectional switches arranged as a matrix [6-8, 20-22]. By using various switching techniques, it is possible to generate output voltage waveforms with various frequencies and amplitudes to satisfy the load requirements. The output voltage waveforms are constructed by joining together selected segments of the input voltage waveforms. Each switch is characterized by a switching function defined as follows:

$$
S_{K j}(t)=\left\{\begin{array}{cc}
1 & \text { switch closed } \\
0 & \text { switch open }
\end{array}\right.
$$

where $K=\{A, B, C\}$ and $j=\{a, b, c\}$ represent the input side and output side of the MC respectively. If $t_{K j}$ denotes the time during which the switch $S_{K j}$ is on and $T_{S}$ representsthe switching period, then the duty cycle of the switch $S_{K j}$ is given by:

$$
m_{K j}(t)=\frac{t_{K j}(t)}{T_{s}}
$$

Therefore, the modulation matrix is obtained as:

$$
M=\left[\begin{array}{lll}
m_{A a}(t) & m_{B a}(t) & m_{C a}(t) \\
m_{A b}(t) & m_{B b}(t) & m_{C b}(t) \\
m_{A c}(t) & m_{B c}(t) & m_{C c}(t)
\end{array}\right]
$$

The output voltages can be synthesized by selecting the appropriate combination of these switches. The control of the MC must comply with two basic rules. First, any two input terminals should never be connected to the same output line to prevent short-circuit, because the MC is fed by a voltage source. Second, an output phase must never be open-circuited, owing to the absence of a path for the inductive load current which leads to the over-voltages. The above two constraints can be expressed as:

$$
\left\{\begin{array}{l}
m_{A a}(t)+m_{B a}(t)+m_{C a}(t)=1 \\
m_{A b}(t)+m_{B b}(t)+m_{C b}(t)=1 \\
m_{A c}(t)+m_{B c}(t)+m_{C c}(t)=1
\end{array}\right.
$$

when these rules are provided, the $3 \times 3$ matrix convertercan allow only 27 different switching states among the possible 512 switching combinations.

Venturini's algorithm control gives unlimited output frequency, sinusoidal input current and output voltage waveforms and controlled input displacement factor. The modulation strategy used in this paper is 
based on a simplified form of the Venturini's algorithm and was proposed by Korti [23-25]. This approach provides a control algorithm with unity input displacement factor and is suitable for real-time implementation. Instead of determining each time point and the zero-crossing point of the input voltage waveform, the simplified form of Venturini's algorithm is identified in each sequential time in terms of threephase input voltages. For unity power factor, the conduction time of the switch placed between input phase $\beta$ and output phase $\gamma$ can be expressed as:

$$
T_{\beta \gamma}=T_{s}\left[\frac{1}{3}+\frac{2 V_{0 \gamma} V_{i \beta}}{3 V_{i m}^{2}}+\frac{2 q}{9 q_{m}} \sin \left(\omega_{i} t+\varphi_{\beta}\right) \sin \left(3 \omega_{i} t\right)\right]
$$

where $\varphi_{\beta}$ refers to the phase angle of $\mathrm{A}, \mathrm{B}, \mathrm{C}$ input phases $(0,2 \pi / 3,4 \pi / 3), q_{m}$ is the maximum voltage ratio (0.866), $q$ the desired voltage ratio, Vim represents the peak of the input voltage, $T s$ is the sampling period, $V_{i \beta}$ is the instantaneous value of the relevant input voltage phase and $\omega_{i}$ denotes the input angular frequency. The Output voltage $V_{0 \gamma}$ is expressed as:

$$
V_{0 \gamma}=q V_{i m} \cos \left(\omega_{0} t+\varphi_{\gamma}\right)-\frac{q}{6} V_{i m} \cos \left(3 \omega_{0} t\right)+\frac{1}{4} \frac{q}{q_{m}} V_{i m} \cos \left(3 \omega_{i} t\right)
$$

where $\varphi_{\gamma}$ is the phase angle of $a, b, c$ output phases $(0,2 \pi / 3,4 \pi / 3)$ and $\omega_{0}$ is the output frequency.

To control the output voltage of the MC it is necessary to calculate the conduction times of the switches for each sampling period to get a voltage with variable frequency and amplitude, especially in systems requiring closed-loop operation. In this simplified form of Venturini's algorithm [9-10], the maximum values of the input and output voltages must be known to calculate the voltage ratio, $q$ in each sampling period. These values can be calculated using (8) to (12).

$$
\begin{aligned}
& V_{i m}^{2}=\frac{4}{9}\left(V_{A B}^{2}+V_{B C}^{2}+V_{A B} V_{B C}\right) \\
& \omega_{i} t=\tan ^{-1}\left[\frac{V_{B C}}{\sqrt{3}\left(\frac{2}{3} V_{A B}+\frac{1}{3} V_{B C}\right)}\right] \\
& V_{0 m}^{2}=\frac{2}{3}\left(V_{a}^{2}+V_{b}^{2}+V_{c}^{2}\right) \\
& \omega_{0} t=\tan ^{-1}\left(\frac{V_{b}-V_{c}}{\sqrt{3} V_{a}}\right) \\
& q=\sqrt{\frac{V_{0 m}^{2}}{V_{i m}^{2}}}
\end{aligned}
$$

Figure 2 shows an example for calculating the conductions times of these switches $\left(t_{A a}, t_{B a}\right)$ using Simulink blocks. Subsystem (A) implements (6) to (12). This produces the first output phase $a\left(V_{o a}\right)$ of the MC. The other two output phases $(b, c)$ are not shown, since they are generated in the same way except they are shifted by $120^{\circ}$ and $240^{\circ}$ respectively. Figure 3 shows the details of Simulink subsystem block (B) of Figure 2. It shows an example of generating the pulses of these switches $\left(S_{A a}, S_{B a}, S_{C a}\right)$ placed between $\beta\{A, B, C\}$ inputphases and $\gamma$ output phase a $\left(V_{o a}\right)$ according to (14) see Figure 4.

As shown in Figure 4, the waveforms $\mathrm{X}$ and $\mathrm{Y}$ are obtained by comparing a saw-tooth with the selected switching frequency and the calculated duty cycles. Finally, the gate drive signals $\left(S_{K j}(t)\right)$, which control the turn-on-time of the power switches are obtained according to the logic statements in (13) by using the duty cycles Consequently, only the duty cycles of six switches are sufficient to calculate the gate signals for allthe power switches $[23,25]$.

$$
\left\{\begin{array} { c } 
{ X = t _ { A j } } \\
{ Y = t _ { A j } + t _ { B j } }
\end{array} \Rightarrow \left\{\begin{array}{l}
S_{A j}=X \\
S_{B j}=\operatorname{not}(X) \text { and }(Y) \\
S_{C j}=\operatorname{not}(X) \text { and } \operatorname{not}(Y)
\end{array}\right.\right.
$$




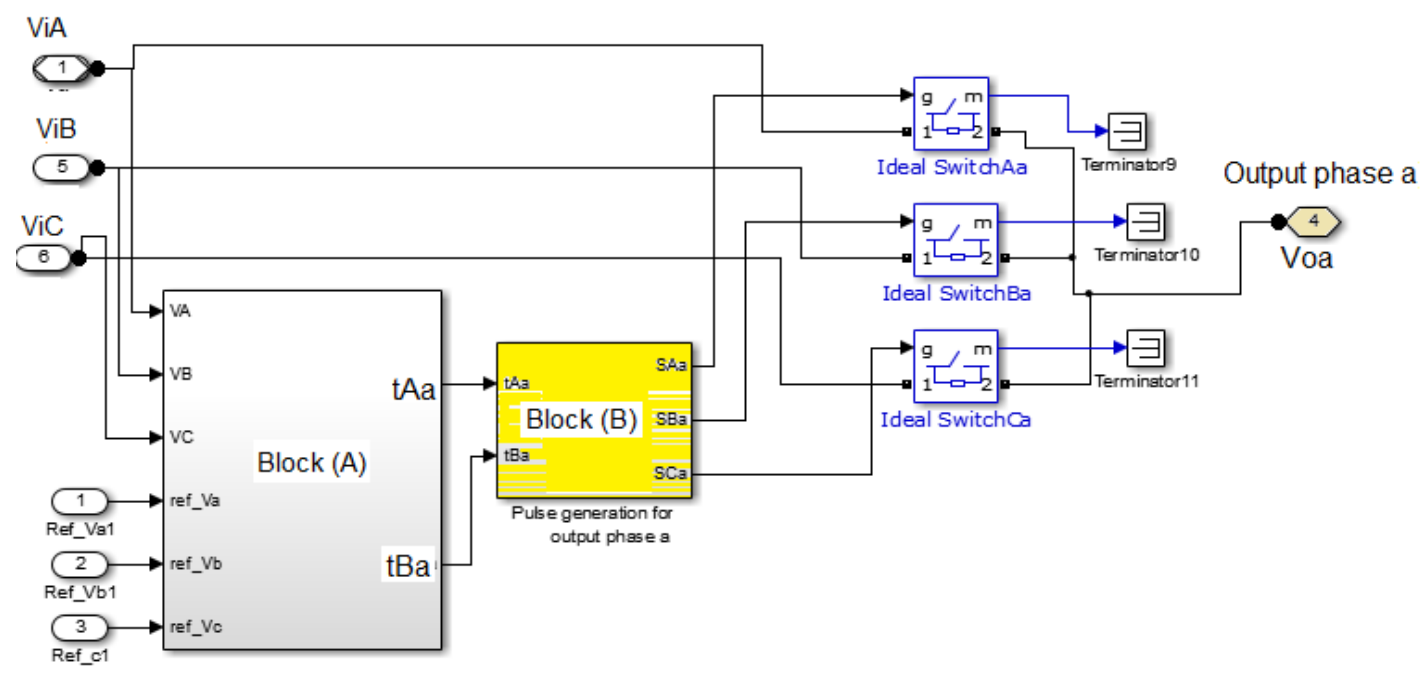

Figure 2. Schematic representation of the first output a $\left(V_{o a}\right)$ of AC-AC three phases MC

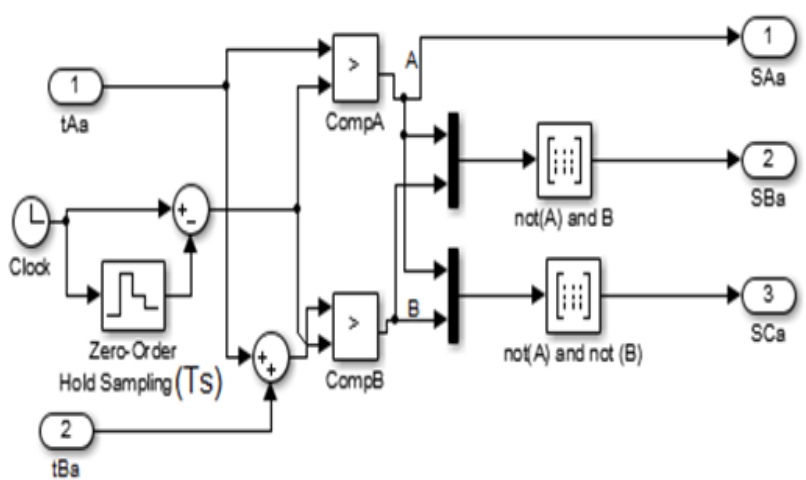

Figure 3. Pulses generation for output of phase $a$

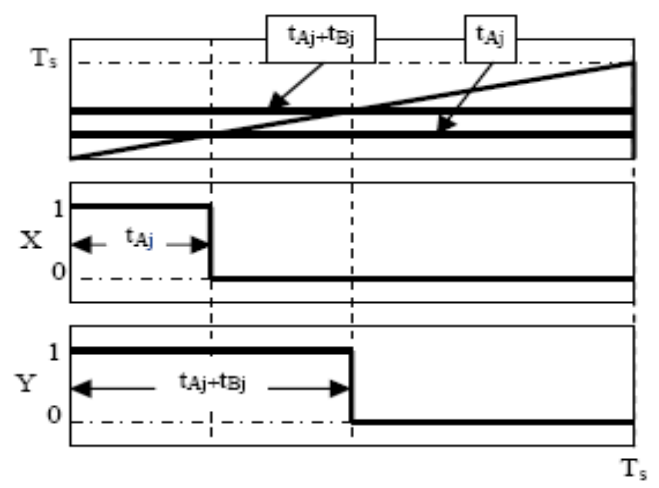

Figure 4. Turn-on-times of the power switches

\subsection{PM synchronous motor (PMSM) drive}

Without loss of generality, a surface-mounted PM machine is assumed and its governing equations can be represented in the rotor $\mathrm{d}-\mathrm{q}$ axis reference frame as in $[2,5]$ :

$$
\left\{\begin{array}{c}
\frac{d i_{d}}{d t}=-\frac{R}{L_{d}} i_{d}+\frac{\omega L_{q} i_{q}}{L_{q}}+\frac{v_{d}}{L_{d}} \\
\frac{d i_{q}}{d t}=-\frac{R}{L_{q}} i_{q}-\frac{\omega L_{d} i_{d}}{L_{q}}+\frac{v_{q}-K_{e} \omega_{m}}{L_{q}}
\end{array}\right.
$$

The mechanical equation of the motor is:

$$
\frac{d \omega_{m}}{d t}=\frac{K_{T}}{J} i_{q}-\frac{B}{J} \omega_{m}-\frac{T_{L}}{J}
$$

where $i_{d}, i_{q}, v_{d}, v_{q}$ are the $d$ - and $q$-axis components of currents and voltages, respectively, $R$ is the phase resistance, and $L_{d}$ and $L_{q}$ are the $d$ - and $q$ - axis inductances.

For a surface-mounted PM machine $L_{d}=L_{q} ; T_{e m}=K_{T} i_{q}$ is the electromagnetic torque with $K_{T}=$ $3 p \psi_{m} / 2$ and $K_{e}=p \psi_{m}$ are the torque andback-emf constants respectively, $\psi_{m}$ is the permanent magnet flux. The electrical angular frequency $\omega$ is related to the angular speed of the machine $\omega_{m}$, by $\omega=p \omega_{m}$, where $p$ is the number of pole-pairs. $J$ and $B$ are the combined moment of inertia and viscous damping coefficient of the machine and drive system, respectively, and $T_{L}$ is the load torque. 


\section{PROPOSED CONTROL SCHEME OF THE MATRIX CONVERTER FED PMSM}

\subsection{Field oriented control of PMSM}

In FOC [5], the control objective is to maintain a zero $i_{d}$ and regulate $i_{q}$ according to its demand. Since $i_{d}$ and $i_{q}$ are influenced by the $v_{d}$ and $v_{q}$ see Figure 5, to compensate for the coupling terms in the d-q axis currents, two new control inputs $v_{d}^{\prime}$ and $v_{q}^{\prime}$, are used andaregiven by:

$$
\begin{aligned}
& v_{d}^{\prime}=v_{d}+\omega L_{q} i_{q} \\
& v_{q}^{\prime}=v_{q}-\omega L_{d} i_{d}
\end{aligned}
$$

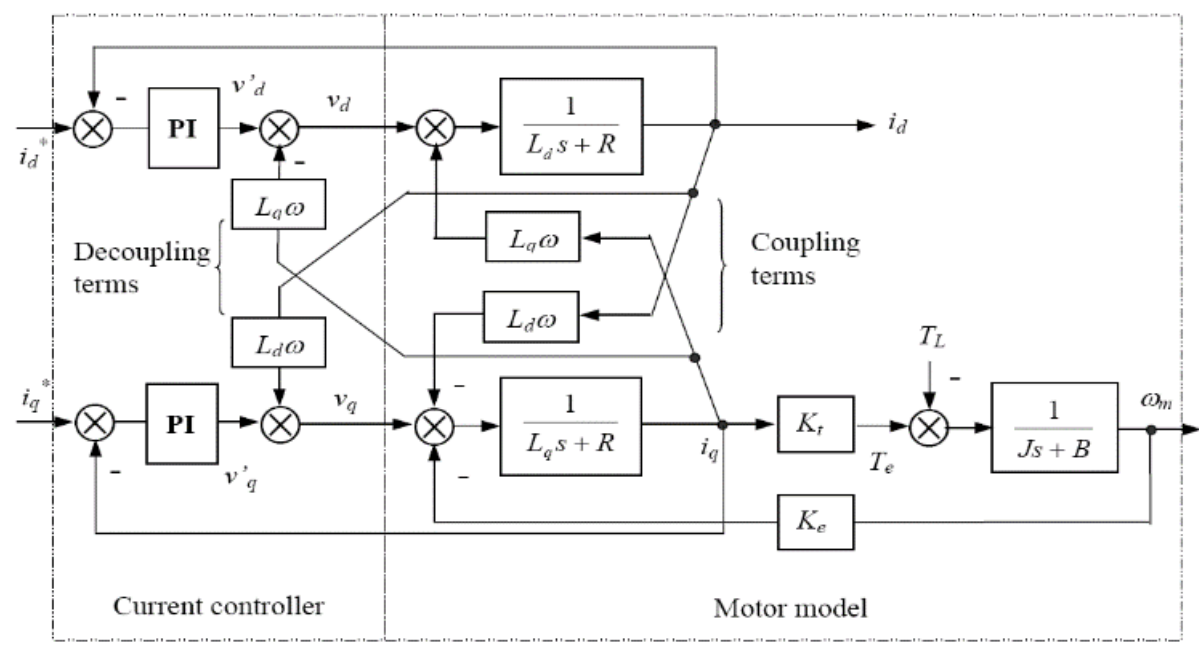

Figure 5. FOC scheme in $d-q$ reference frame

The resultant $d, q$ axis current dynamics are governed by:

$$
\begin{gathered}
\mathrm{Ri}_{\mathrm{d}}+\mathrm{L}_{\mathrm{d}} \frac{\mathrm{di}_{\mathrm{d}}}{\mathrm{dt}}=\mathrm{v}_{\mathrm{d}}^{\prime} \\
\mathrm{Ri}_{\mathrm{q}}+\mathrm{L}_{\mathrm{q}} \frac{\mathrm{di}_{\mathrm{q}}}{\mathrm{dt}}=\mathrm{v}_{\mathrm{q}}^{\prime}-\mathrm{K}_{\mathrm{e}} \omega_{\mathrm{m}}
\end{gathered}
$$

Since the current response is much faster than the speed response, the effect of back-emf on the $q$ axis current may be neglected in the controller design. The currents control loop $i_{d}$ and $i_{q}$ is represented by the Figure 6. The same loop control is valid for the $q$-axis current by substituting the index $d$ by $q$.

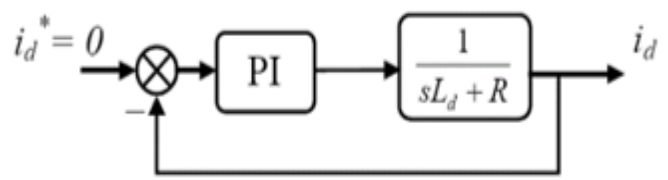

(a)

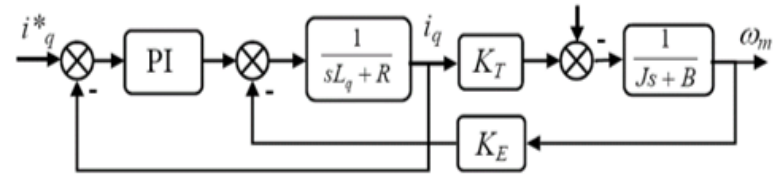

(b)

Figure 6. Decoupled $d$ - $q$ current control loop, (a) d-axis current control loop, (b) q-axis current control loop

\subsection{Current controllers}

The stator currents $\left(i_{d}\right.$ and $\left.i_{q}\right)$ are controlled by type Proportional and Integral (PI) regulators whose transfer function is:

$$
\frac{k_{i i}+k_{p i} S}{s}
$$


with $k_{i i}, k_{p i}$ represent the integral and proportional gains ofthe PI currents controller, $\tau_{e}=L_{d} / R=L_{q} / R$ are time constants. Using the following pole-zero cancelling $k_{p i} / k_{i i}=L_{d} / R$, the closed loop transfer function for both $d$ and $q$ axis currents is:

$$
\frac{i_{d, q}^{*}(s)}{i_{d, q}(s)}=\frac{\frac{k_{i i}}{R s}}{1+\frac{k_{i i}}{R s}}=\frac{k_{i i}}{R s+k_{i i}}=\frac{1}{\frac{R}{k_{i i}} s+1}
$$

To achieve the desired time constant of $1 \mathrm{~ms}$, then:

$R / k_{i i}=0.001$ or $k_{i i}=R / 0.001$

$k_{i i}=4.2 / 0.001=4200$.

$k_{p i}=k_{i i} \tau_{e}=4200 * 0.0072 / 4.2=7.2$

\subsection{Speed controllers design}

\subsubsection{PI controller:}

The block diagram of the speed control is given by Figure 7 [12-14]:

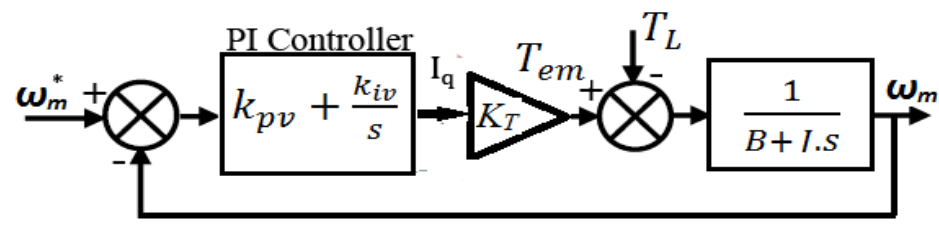

Figure 7. Bloc diagram of PI controller

where $k_{i v}$ and $k_{p v}$ the integral and proportional gains of the speed PI control loop. The closed-loop transfer function is:

$$
\frac{\omega_{m}}{\omega_{m}^{*}}=\frac{1+\frac{k_{p v}}{k_{i v}} s}{1+\frac{B+k_{T} k_{v}}{k_{T} k_{i v}} s+\frac{J}{k_{T} k_{i v}} s^{2}}=\frac{1+\tau s}{1+\frac{2 \xi}{\omega_{n}} s+\frac{s^{2}}{\omega_{n}^{2}}}
$$

Equating the two closed-loop transfer functions yields:

$$
\left\{\begin{array}{c}
\tau=\frac{k_{p v}}{k_{i v}} \\
\frac{2 \xi}{\omega_{n}}=\frac{B+k_{T} k_{p v}}{k_{T} k_{i v}} \\
\frac{1}{\omega_{n}^{2}}=\frac{J}{k_{T} k_{i v}}
\end{array}\right.
$$

Solving the system of equations, the PI speed controller gains are obtained by:

$$
k_{i v}=\frac{J \omega_{n}^{2}}{k_{T}} k_{p v}=\frac{2 \xi J \omega_{n}-B}{k_{T}}
$$

In this work, the damping ratio and natural frequency are set to $\xi=1$ and $\omega_{n} \approx 62,8 \mathrm{rad} /$ srespectively and based on the motor parameters the gains of the PI controller are obtained as: $k_{i v}=34.60$ and $k_{p v}=1.1$.

\subsubsection{IP controller}

The block diagram of the speed control is shown in Figure 8. The proportional gain of the conventional PI is moved from the forward loop to the feedback loop [15-17]. 


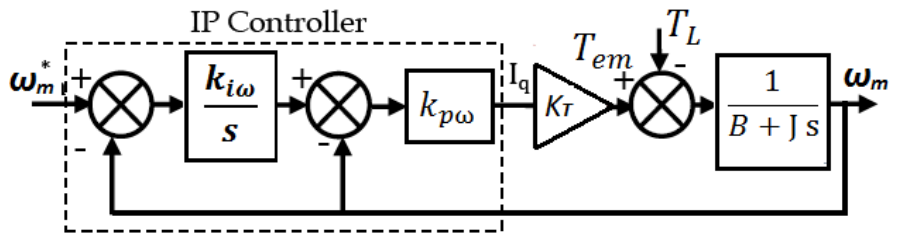

Figure 8. Block diagram of IP controller

where $k_{i \omega}$ and $k_{p \omega}$ denote the integral and proportional gains of the speed IP control loop. With reference to Figure 8, the closed-loop transfer function is:

$$
\frac{\omega_{m}}{\omega_{m}^{*}}=\frac{\frac{k_{p} k_{T} k_{i \omega}}{J}}{s^{2}+\frac{B+k_{T} k_{p} \omega}{J} s+\frac{k_{p} \omega^{k} k_{i \omega}}{J}}
$$

Not that, with IP controller, the closed-loop transfer function does not have any zero. The IP controller ensuresa good dynamic and steady-state response in both tracking or regulation modesdespite torque load variations (disturbance). Let the desired closed-loop transfer function be:

$$
T(s)=\frac{\omega_{n}^{2}}{s^{2}+2 \xi \omega_{n} s+\omega_{n}^{2}}
$$

As shown in (21) and (22), the proportional and integral gains can be expressed as:

$$
\left\{\begin{aligned}
k_{p \omega} & =\frac{2 \xi J \omega_{n}-B}{k_{T}} \\
k_{i \omega} & =\frac{J \omega_{n}^{2}}{2 \xi J \omega_{n}-B}
\end{aligned}\right.
$$

Choosing a damping ratio $\xi=1$ and natural frequency $\omega_{n} \approx 62.8 \mathrm{rad} / \mathrm{s}$ and using the motor parameters the IP controller gains are obtained as: $k_{p \omega}=1.1 ; k_{i \omega}=31.45$.

\subsection{Implementation of the control scheme}

The above discussion only focuses on the control requirement. To implement this control scheme, it is necessary to form the $i_{d}$ and $i_{q}$ current componentsfor the current feedback loop, and the control outputs that can be realized in the stator reference. The block diagram of the proposed control scheme is shown in Figure 9. The phase currents are measured, and transformed into $d, q$ components. The $\theta$ angle required for the transformation is obtained from the position sensor/transducer, such as an encoder or resolver. The angular velocity information is needed for the current loop decoupling, and is usually obtained by differentiating the position signal. The output of the current controller is the $v_{d}$ and $v_{q}$, which are transformed back to voltage signals in the A, B, C system. These signals are then used to control the MC via a simplified form of the Venturini's algorithm, so that the required phase voltages are applied to the motor terminals to achieve FOC.

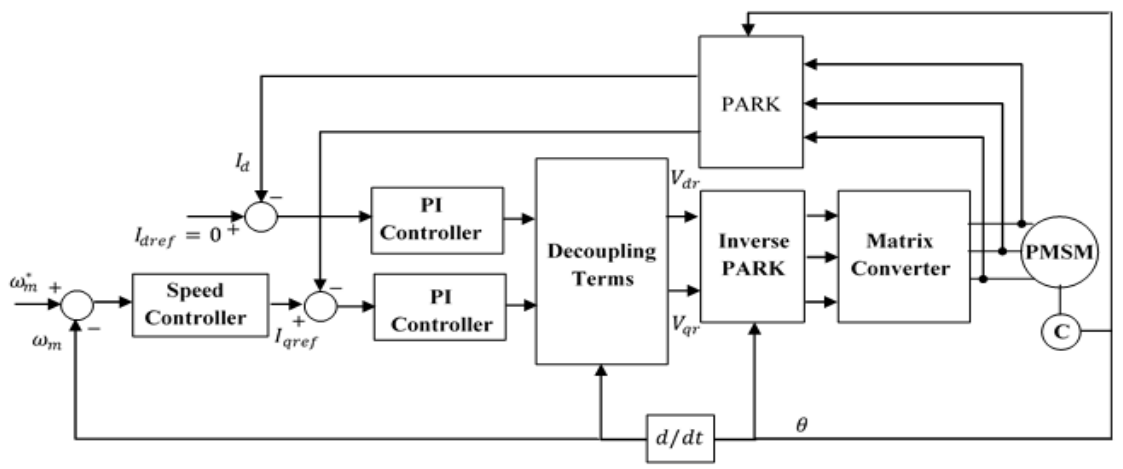

Figure 9. Block diagram of brushless PM AC drives with FOC 


\section{SIMULATION RESULTS}

The entire drive system model is implemented in Matlab/Simulink as shown in Figure 10. The parameters of the PMSM and the simulation parameters for the closed loop system used in this simulation study aregiven in the appendix. The simulation is runfor $0.55 \mathrm{sec}$. Two simulation scenarios are considered: 1) load torque changes from $5 \mathrm{~N} . \mathrm{m}$ to $7 \mathrm{~N} . \mathrm{m}$ at $t_{1}=0.15 \mathrm{sec}$, from $7 \mathrm{~N} . \mathrm{m}$ to $10 \mathrm{~N} . \mathrm{m}$ at $t_{2}=0.25 \mathrm{sec}$ with constant reference angular speed $\omega_{\text {ref }}=157 \mathrm{rad} / \mathrm{s}$ and. 2) speed reference changes from $157 \mathrm{rad} / \mathrm{s}$ to140 $\mathrm{rad} / \mathrm{s}$ at $t_{3}=0.35 \mathrm{sec}$, from $140 \mathrm{rad} / \mathrm{sec}$ to $170 \mathrm{rad} / \mathrm{sec}$ at $t_{4}=0.45 \mathrm{sec}$ with constant reference load torque of $T_{L}=10 \mathrm{~N} . \mathrm{m}$.

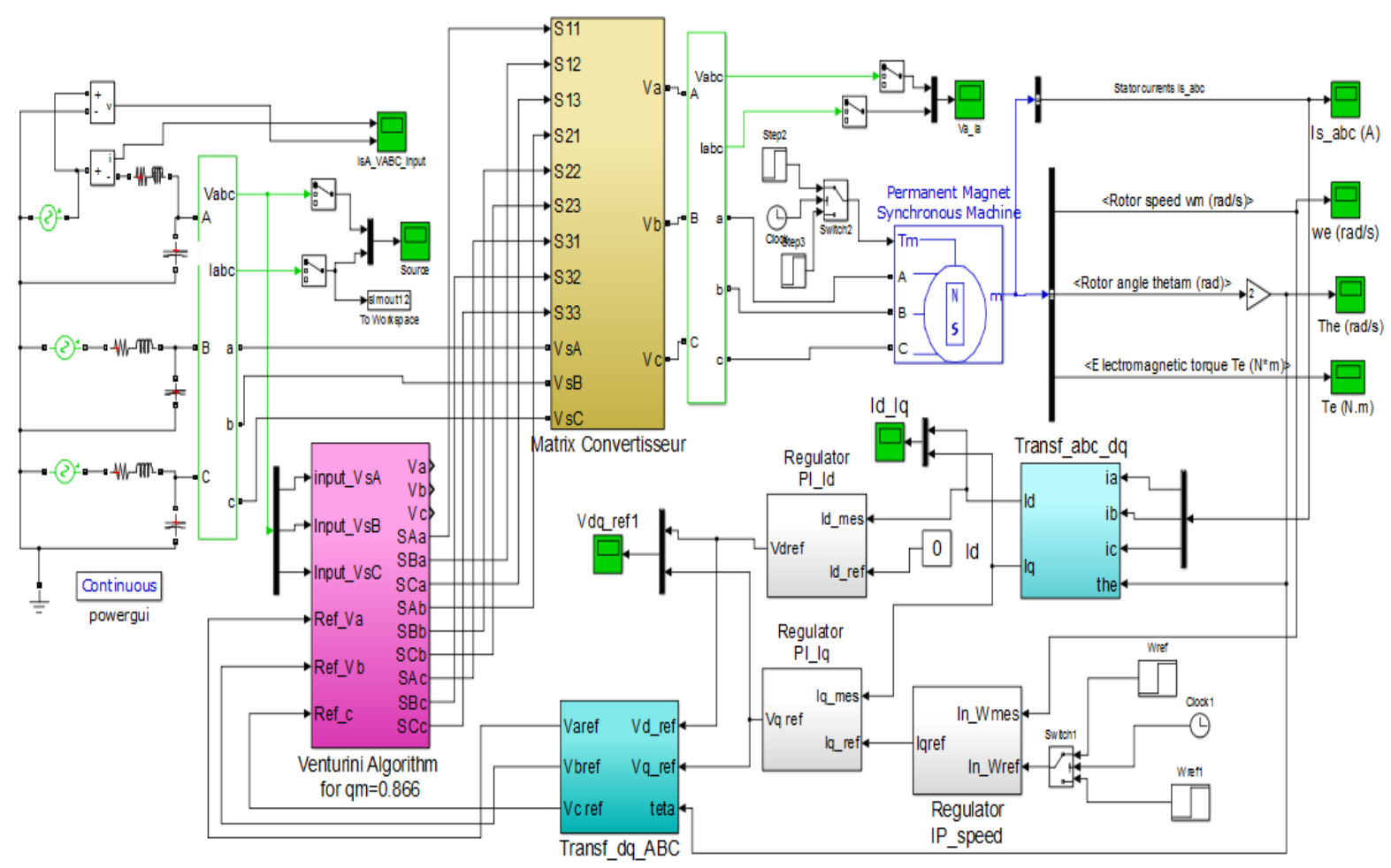

Figure 10. Simulink model of brushless PM AC drives with FOC

\subsection{Input characteristics}

The MCs also have sinusoidal input voltage and sinusoidal current waveforms according to the assumption made for the direct MC model. Together with this, another feature of MC must be verified for the model is the input power factor control. Looking at Figure 11, it can be observed that the control operates to keep the MC input current in phase with the corresponding input phase voltage. These plots demonstrate the validity of the MC input characteristics.

As far as the input power quality is concerned it must be emphasized that there is a significant reduction of the low order current harmonic components carried out by direct MC compared to the dioderectified voltage source inverters. Since the MC is a switch-mode device, the harmonic components are at the switching frequency $\left(f_{s}=10 \mathrm{Khz}\right)$ and multiples of it. Therefore, the reduction on the harmonic contents can be easily obtained by using an input filter. However, this is not possible for the diode-rectified structures due to the subharmonic contents. The harmonic spectrums of unfiltered and filtered input current waveforms are shown in Figure 12.

The high frequencies components are attenuated and the total harmonic distortion (THD) of the input current isreduced to about $3.49 \%$. However, the designed filter produces a small displacement between the input voltage and current with the input displacement factor (IDF) approximately of 0.98 as shown in Figure 11(middle). This provesthat the input filter is used to improve the power quality of the input current. 

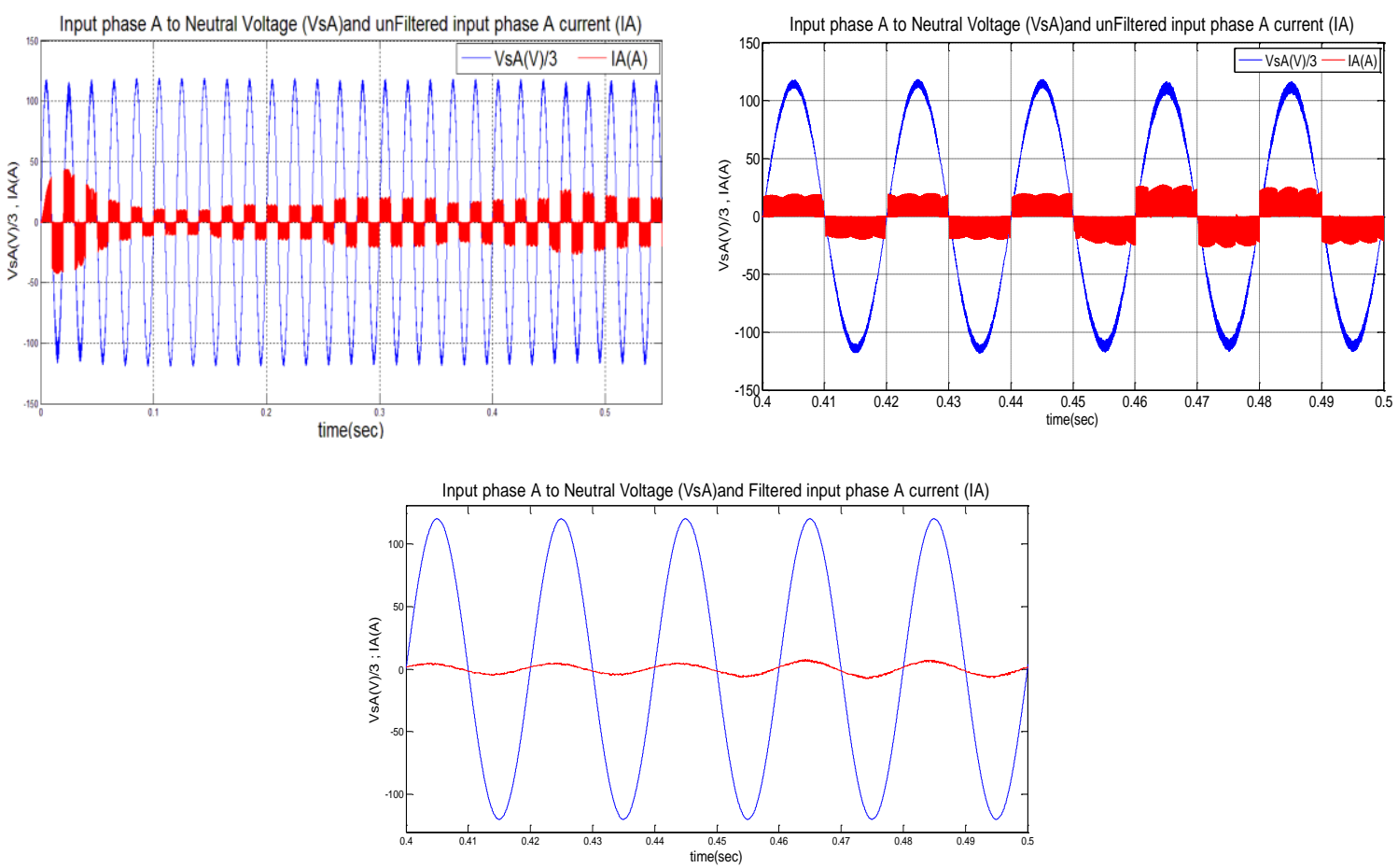

Figure 11. Unfiltered input current $I_{A}$ and $V_{S A} / 3$ (left), zoom of unfiltered input current $I_{A}$ and $V_{S A} / 3$ (right) and zoom of filtered input current $I_{A}$ and $V_{S A}$ (middle)
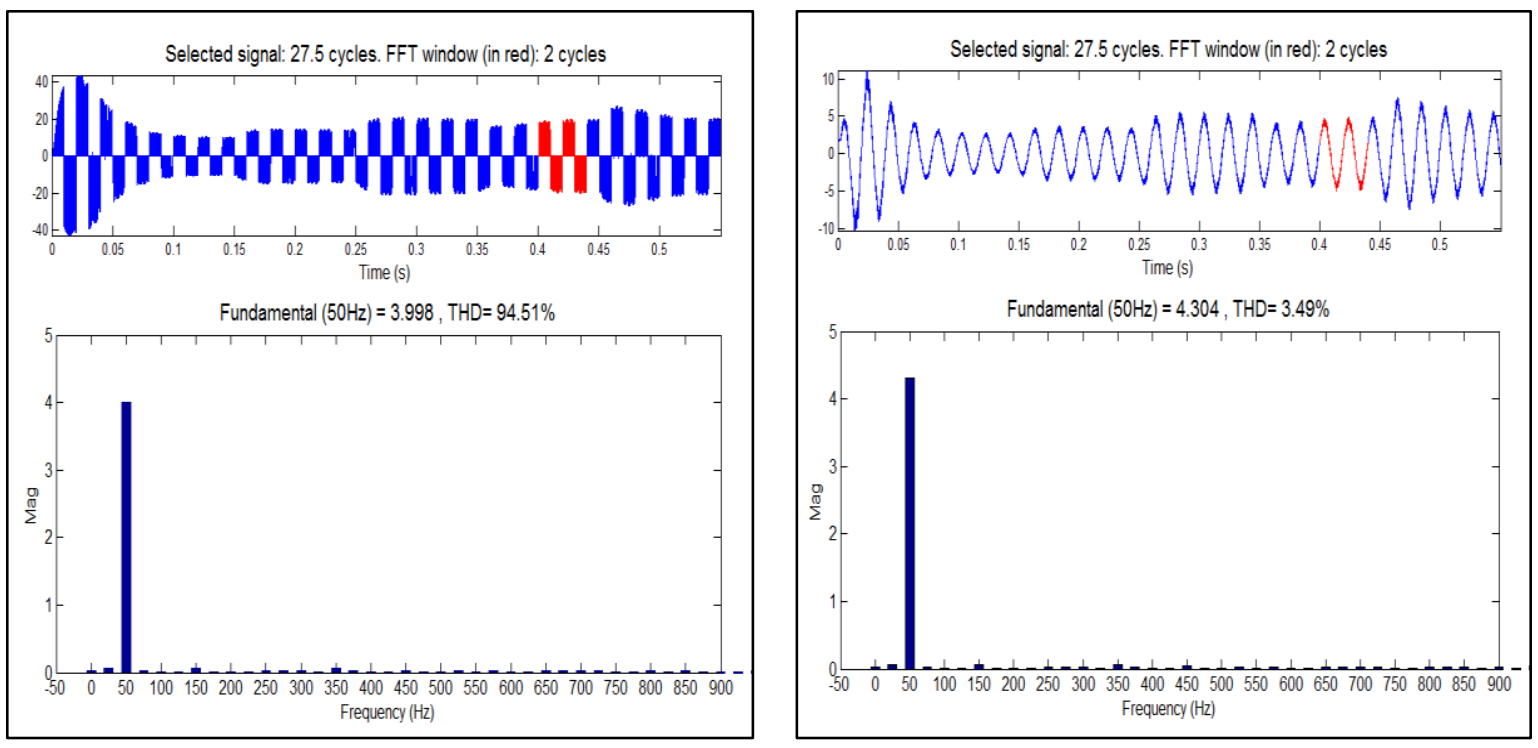

Figure 12. Unfiltered (left) and filtered (right) of input phase current $I_{A}$ and its harmonic spectrum

\subsection{Output characteristics}

The transient and steady-state performance of this PMSM drive system has been tested with the speed controllers namely IP and PI through four cycles. For time between $0 \mathrm{sec}$ to $t_{1}=0.15 \mathrm{sec}$, the reference angular speed is set to $\omega_{\text {ref }}=157 \mathrm{rad} / \mathrm{s}$ and a load torque of $T_{L}=5 \mathrm{Nm}$ is applied from the start. The observed phase current waveforms are shown in Figure 13.

The current exhibits an initial overshoot due to the high starting torque, but quickly settles to as a uniform sinusoidal waveformwithin $0.067 \mathrm{sec}$. It can also be observed that each waveform is displaced by $120^{\circ}$ from each other. The observed currents $I_{d}$ and $I_{q}$ and the torque $T_{e}$ waveforms are shown in Figure 14. 
Again, the starting torque and current $I_{q}$ are high but quickly settle to their $5 \mathrm{Nm}$ and 10 A respectively within $0.08 \mathrm{sec}$. Since FOC is used the value of $I_{d}$ is zero.

The observed angular speed waveforms are shown in Figure 15. The speed increases linearly from 0 to $157 \mathrm{rad} / \mathrm{sec}$ and settles in the case of the IP regulator. On the other hand, the speed overshoots to around $165 \mathrm{rad} / \mathrm{sec}$ initially, but soon settles to $157 \mathrm{rad} / \mathrm{sec}$ and remains stable for PI.

In Figures. 13 to 15, the load torques change (increases) from 5 N.m to 7 N.m at $t_{1}=0.15$ sec, and from $7 \mathrm{~N} . \mathrm{m}$ to $10 \mathrm{~N} . \mathrm{m}$ at $t_{2}=0.25 \mathrm{sec}$ with constant reference angular speed $\omega_{\text {ref }}=157 \mathrm{rad} / \mathrm{s}$. The speed drops and the phase current amplitude also increases after a small transition period the controller action (IP or PI) brings the angular speed back to the reference speed of $157 \mathrm{rad} / \mathrm{sec}$. The torque $T_{e}$ produced by the motor also increases to counter balance the load torque applied to it, which causes a corresponding increase in quadrature axis current $I_{q}$ as well and $I_{d}=0$.

When the angular speed reference changes from $157 \mathrm{rad} / \mathrm{s}$ to $140 \mathrm{rad} / \mathrm{s}$ at $t_{3}=0.35 \mathrm{sec}$, from 140 $\mathrm{rad} / \mathrm{sec}$ to $170 \mathrm{rad} / \mathrm{sec}$ at $t_{4}=0.45 \mathrm{sec}$ with constant reference load torque $\left(T_{L}=10 \mathrm{~N} . \mathrm{m}\right)$, the corresponding torque (response of the system is shown in Figure14 and the electromagnetic torque drops and then quickly settles and follows the load torque, which has a constant value of $10 \mathrm{~N} . \mathrm{m}$. It is clear from Figure13 that the stator current is kept constant after a short transient period during sudden reference speed variations, especially in the case of the PI regulator.

In Figure 15 are shown the speed responses under different operating conditions such as step changes in the reference speed or sudden changes in the load. It can also be observed that the load disturbance influences the speed responses produced by using PI controller but the IP has better transient response see Figures 13 to 14). IP controller gives better results in terms of without exceeded and fast response to speed reference changes.

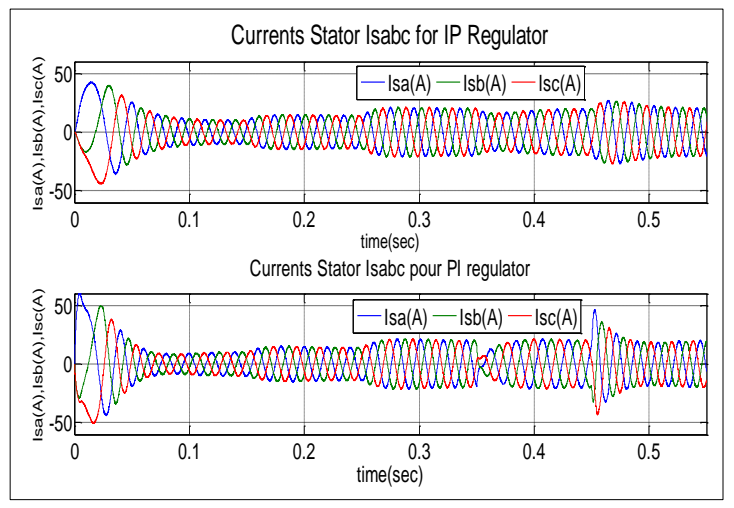

Figure 13. Phase current stator waveforms with IP and PI regulators

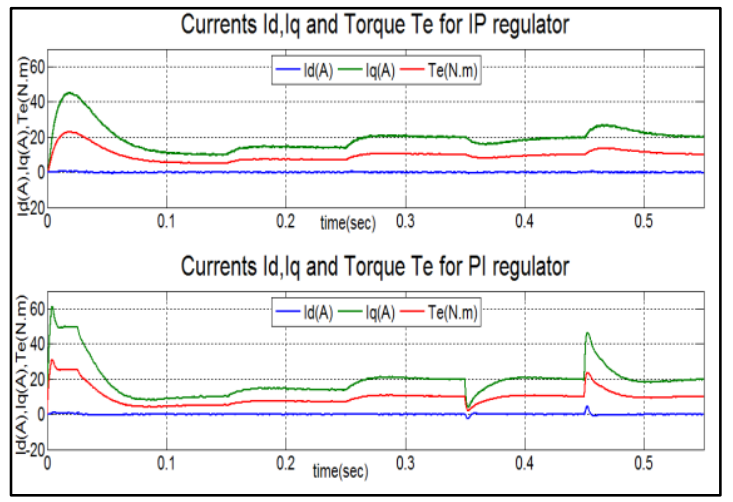

Figure 14. Currents $I_{d}, I_{q}$ and torque $T_{e}$ waveforms with IP and PI regulators

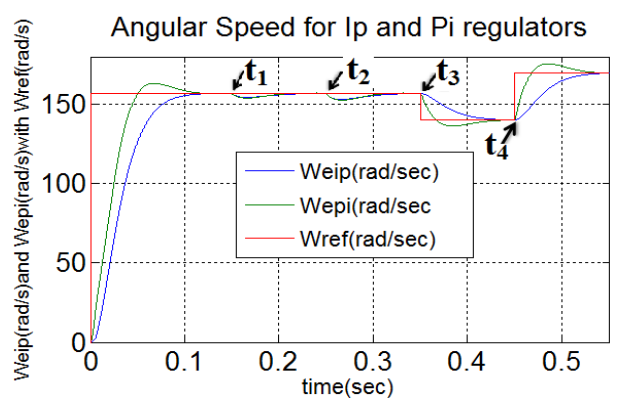

Figure 15. Angular speed responses with IP and PI regulators

\section{CONCLUSION}

The work presented in this paper is intended to demonstrate, the successful application of the matrix converter with its modulation technique based on a simplified form Venturini's modulation algorithm toa 
PMSM drive system. The matrix converter is a switch-mode device and generates harmonic components especially at switching frequencies. In this study, the harmonic spectra of the currents and voltages are analyzed. It has been shown that an unfiltered matrix converter highly pollutes the utility grid. As a result, a small filter with the cable effect was designed and simulated with the matrix converter model.

It was observed that the dominant frequency harmonics especially at switching frequency and its multiples were suppressed. Also, the high harmonic contents are not seen in the output currents waveforms because the motor (i.e. load with impedance equivalent R-L) attenuates these high frequency harmonics. Thus, the effect of these harmonics on the electromagnetic torque is negligible. The performance of the PMSM drive with PI and IP controllerswas compared and the results have shown that IP speed controller improved the transient and steady-state performances of PMSM drive, in regulation mode and does not exhibits excessive overshoots, thus, reducing the settling time as compared to the classic PI controller which is quite sensitive to disturbances.

\section{REFERENCES}

[1] S. Raj, R. Aziz, M. Z. Ahmad, "Influence of pole number on the characteristics of permanent magnet synchronous motor (PMSM)," Indonesian Journal of Electrical Engineering and Computer Science, vol. 13, no. 3, pp. 1318-1323, 2019.

[2] Ganapathy Ram, Santha K. R., "Review of Sliding Mode Observers for Sensorless Control of Permanent Magnet Synchronous Motor Drives," International Journal of Power Electronics and Drive Systems (IJPEDS), vol. 9, no. 1, pp. 46-54, 2018.

[3] Mouna Es-Saadi, Mohamed Khafallah, Hamid Chaikhy, "Using the Five-Level NPC Inverter to Improve the FOC Control of the Asynchronous Machine," International Journal of Power Electronics and Drive Systems (IJPEDS), vol. 9, no. 4, pp. 1457-1466, 2018.

[4] R. Hammami, I. Ben Ameur and K. Jelassi, "Performance evaluation of fractional order controller for induction machine control and comparative study between FOC PI \& FOC FOPI," 2017 18th International Conference on Sciences and Techniques of Automatic Control and Computer Engineering (STA), Monastir, pp. 272-277, 2017.

[5] S. Wahid, H. Khammari and M. F. Mimouni, "On some parametric and phase space singularities in PMSM submitted to FOC drive," 2015 7th International Conference on Modelling, Identification and Control (ICMIC), Sousse, pp. 1-7, 2015.

[6] Rahimi Baharom, Abdul Muin Awang, "Development of four quadrant operation of DC to DC converter using single phase matrix converter," Indonesian Journal of Electrical Engineering and Computer Science, vol. 16, no. 3, pp. 1249-1256, 2019.

[7] Muldi Yuhendri, Ahyanuardi Ahyanuardi, Aswardi Aswardi, "Direct Torque Control Strategy of PMSM Employing Ultra Sparse Matrix Converter," International Journal of Power Electronics and Drive Systems (IJPEDS), vol. 9, no. 1, pp. 64-72, 2018.

[8] K. Selvakumar, R. Palanisamy, Arul Rayappan Stalin, P. Gopi, P. Ponselvin, K. Saravanan, "Simulation of 3-phase matrix converter using space vector modulation," International Journal of Electrical and Computer Engineering (IJECE), vol. 9, no. 2, pp. 909-916, 2019.

[9] E. Purwanto, F. D. Murdianto and G. Basuki, "Venturini Modulation Method For Matrix Converter," 2019 International Electronics Symposium (IES), Surabaya, Indonesia, pp. 601-605, 2019

[10] K. Gilda, "Mathematical Modelling of Matrix Converter," 2018 IEEE International Students' Conference on Electrical, Electronics and Computer Science (SCEECS), Bhopal, pp. 1-6. 2018.

[11] E. Erdem, Y. Tatar and S. Sünter, "Effects of input filter on stability of matrix converter using venturini modulation algorithm," SPEEDAM 2010, Pisa, pp. 1344-1349, 2010.

[12] Naveen Goel, Saji Chacko, R. N. Patel, "A parameter less stochastic optimization technique for tuning of speed PI controller of DTC induction motor drive," IAES International Journal of Robotics and Automation (IJRA), vol. 8, no. 2, pp. 105-112, 2019.

[13] S. Salimin, M. Armstrong, S.A. Jumaat, R. Hamdan, "Comparison between PI, PR+HC, and modified PR+HC current controller in inverter system," Indonesian Journal of Electrical Engineering and Computer Science, vol. 13, no. 3, pp. 1167-1174, 2019.

[14] A. Platon, S. Oprea, A. Florescu and S. G. Rosu, "Simple and Digital Implementation of PI Controller Used in Voltage-Mode Control," 2018 10th International Conference on Electronics, Computers and Artificial Intelligence (ECAI), Iasi, Romania, pp. 1-6, 2018.

[15] O. Rabiaa, B. H. Mouna, D. Mehdi and S. Lassaad, "Scalar speed control of dual three phase induction motor using PI and IP controllers," 2017 International Conference on Green Energy Conversion Systems (GECS), Hammamet, pp. 1-6, 2017.

[16] Q. Liu and X. Chang, "Position IP control of a permanent magnet synchronous motor based on fuzzy neural network," 2018 Chinese Control And Decision Conference (CCDC), Shenyang, pp. 1081-1086, 2018.

[17] Xianqing Cao, Liping Fan and Yidong Zhu, "Real-time IP controller based on neural network for permanent magnet synchronous motors," 4th IEEE Conference on Industrial Electronics and Applications, Xi'an, pp. 2345-2349, 2009.

[18] P. D. Laforge, R. R. Mansour and M. Yu, "The Use of Low-Pass Filters as Impedance Inverters for Highly Miniaturized Superconducting Bandstop Filter Designs," IEEE Transactions on Applied Superconductivity, vol. 21, no. 3, pp. 575-578, 2011. 
[19] M. A. E. Latina, M. P. Sejera, J. P. V. Mitra, B. S. Monton and C. S. Pundan, "A Study of the Effect of Integrating Low-Pass Filter in Measuring the Dynamic Performance of a High Speed 8-bit Analog-to-Digital Converter (ADC)," 2018 IEEE 10th International Conference on Humanoid, Nanotechnology, Information Technology, Communication and Control, Environment and Management (HNICEM), Baguio City, Philippines, pp. 1-6, 2018.

[20] J. Riedemann Aros, R. Pena Guinez, R. Cardenas Dobson, R. Blasco Gimenez and J. Clare, "Indirect matrix converter modulation strategies for open-end winding induction machine," in IEEE Latin America Transactions, vol. 12, no. 3, pp. 395-401, 2014.

[21] Y. Ma, X. Ma, P. Li and X. Ren, "A modulation strategy for improving output performance of matrix converter," in CPSS Transactions on Power Electronics and Applications, vol. 4, no. 3, pp. 255-262, Sept. 2019.

[22] A. Trentin, L. Empringham, L. de Lillo, P. Zanchetta, P. Wheeler and J. Clare, "Experimental Efficiency Comparison Between a Direct Matrix Converter and an Indirect Matrix Converter Using Both Si IGBTs and SiC mosfets," in IEEE Transactions on Industry Applications, vol. 52, no. 5, pp. 4135-4145, 2016.

[23] Yakut, Yurdagül Benteşen, Sedat Sunter, and Mehmet Ozdemir, "A control method for driving dual permanent magnet synchronous motors fed by single matrix converter," Tehnicki Vjesnik-Technical Gazette, vol. 24, no. 6, pp. 1977-1984, 2017.

[24] S. Sünter, "A vector controlled matrix converter induction motor drive," PhD Thesis, University of Nottingham, Nottingham, UK, 1995.

[25] Karaca, Hulusi, and Ramazan Akkaya, "Control of Venturini method based matrix converter in input voltage variations," Proceedings of the International Multi Conference of Engineers and Computer Scientists (IMECS), vol. 2, pp. 1412-1416, Hong Kon, 2009. 